LETTER TO EDITOR

\title{
Prognostic Value of Mean Platelet Volume and Platelet to Lymphocyte Ratio in Laryngeal Carcinoma
}

\author{
Sefa Ciftci \\ Department of Biochemistry, Turkiye Yuksek Ihtisas Training and Research Hospital, Ankara, Turkey
}

\begin{abstract}
Mean thrombocyte volume (MPV) and platelet lymphocyte ratio (PLR) from platelet indices used to assess platelet activation and function have been associated with a number of diseases in recent years. Laboratory studies should be considered when evaluating MPV and PLR tests. More detailed studies on MPV and PLR is needed in Laryngeal Carcinoma. J Clin Exp Invest 2016; 7(4): 294-295
\end{abstract}

Keywords: Laryngeal Carcinoma, Prognosis, MPV, PLR.

\section{Dear Editor,}

I read Yilmaz et al. the interesting study 'Prognostic Value of Mean Platelet Volume and Platelet-Lymphocyte Ratio in Laryngeal Carcinoma' published in the last issue of your journal. I congratulate the authors and friends for this study. In addition to studying, I have a few contributors to the parameters for readers and authors.

MPV and PLR tests studying were not informed to the patient and control group on the same day and on the same device, and even the results were given a duration of approximately 12 years. Calibrations and controls are made on a daily basis in laboratory equipments, and patient results may show differences between days due to this reason [2]. It is likely that the devices being operated have changed according to the tender laws. Since each method and device has different characteristics, it is necessary for the reader to know what method they are working with. It is of great importance to study all results on the same day and on the same device in such studies. Communication with the laboratory specialist will reduce measurement uncertainties.

In this study, devices used for automatic blood counting are not specified, and it should be noted that if more than one automatic blood count device is used, MPV results may be significantly affected [3]. It has been reported that MPV measurements can vary by up to $40 \%$ in different whole blood count devices [4].

This parameters can be affected from many diseases and conditions (hypertension, hematologic and renal diseases, heart failure, chronic infections, hepatic disorders, acute inflammatory diseases, autoimmune diseases, other cancers and drug use) [5]. There is no statement that these diseases are excluded from the study. The non-exclusion of these conditions will constitute question marks for the study.

Platelet and lymphocyte counts have different reference intervals according to age and sex [6]. There is a statistically significant difference between age and gender in the comparison of benign and malignant patients in the study. Therefore, the comparison of patients with different age and gender will reduce the value of the results.

Best regards,

\section{Dr. Sefa Ciftci,}

Department of Biochemistry, Turkiye Yuksek Intisas Training and Research Hospital, Ankara, Turkey

Correspondence: Dr. Sefa Çiftçi, Biyokimya Laboratuvarı, Türkiye Yüksek ihtisas Eğitim ve Araştırma Hastanesi, Ankara, Turkey. Received: 12 July 2016, Accepted: 18 December 2016 
Conflict of Interest: The author declares no conflict of interest.

\section{REFERENCES}

1. Beyhan Yılmaz EŞ, Murat Şereflican, Musa Özbay, Vefa Kınıs, Aylin Gül,, Fatma Teke IT. Prognostic Value of Mean Platelet Volume and Platelet to Lymphocyte Ratio in Laryngeal Carcinoma. Journal of Clinical and Experimental Investigations. 2016;7:134-8.

2. Westgard JO, Burnett RW, Bowers GN. Quality management science in clinical chemistry: a dynamic framework for continuous improvement of quality. Clin Chem. 1990;36:1712-6.

3. Ayyıldız H, Kalaycı M. Letter to editor: An evaluation of hemoglobin and hematocrit levels among the patients with skin cancer and healthy individuals. Turkish Journal of Biochemistry 2015;40:92-3.

4. TI. G: Automated hematology instrumentation. In., vol. 2014: UpToDate.

5. Kemal Y, Demirag G, Ekiz K, Yucel I. Mean platelet volume could be a useful biomarker for monitoring epithelial ovarian cancer. J Obstet Gynaecol. 2014;34:515-8.

6. Lim E, Miyamura J, Chen JJ. Racial/EthnicSpecific Reference Intervals for Common Laboratory Tests: A Comparison among Asians, Blacks, Hispanics, and White. Hawaii J Med Public Health. 2015;74:302-10. 